\title{
Frequency Control Method of Isolated Micro-grid Based on Thermostatically Controlled Load
}

\author{
Qingzhu Wan ${ }^{1, a}$, Yuan Bian ${ }^{1, b}$ and Yalan Chen $^{1, c}$ \\ ${ }^{1}$ North China University of Technology, Beijing 100144, China. \\ a13501009879@163.com, b1191796395@qq.com, chenyalanjane@163.com
}

Keywords: Micro-grid, frequency control, thermostatically controlled loads, energy storage system.

\begin{abstract}
With proportion of air conditioners increasing gradually, they can provide certain amount of frequency controlled reserve for micro-grid. To maximize using air conditioners and consider customer comfort, the frequency adjustment model is shown that the quadratic function model of trigger temperature of air conditioner compressor and frequency variation is provided which can be used to regulate respectively trigger temperature of air conditioner under micro-grid frequency rising and falling. This frequency adjustment model combines energy storage system's primary frequency modulation method and secondary frequency modulation method, which is to optimize the micro-grid frequency. Simulation results verify the frequency modulation strategy can effectively improve air conditioners frequency modulation ability and micro-grid frequency modulation effect.
\end{abstract}

\section{Introduction}

The capacity of micro-grid on acceptance of intermittent energy is growing rapidly and the use of thermostatically controlled loads (e.g.,air conditioners) is increasing gradually[1], which is difficult to ensure the stability of the grid frequency. Based on the operating mechanism of traditional micro-grid, peak units and switching out for power consumption limitation used[2] can maintain the stability of the system frequency in the case of new energy power generation shortage and peak loads. In view of the high cost of peak units and the impact on user comfort, energy storage equipment can be introduced as the frequency adjustment reserve capacity. However, it is difficult to be promoted owing to higher cost and limited lifetime. For these reasons, the introduction of demand response technology[3] provides a number of frequency modulation solutions. It can control the loads energy to compensate the new energy output fluctuation and maintain the stability of the micro-grid frequency.

Efforts have been made in the filed of using controllable loads as frequency reserves. The family-friendly controllable loads (e.g., air conditioners, refrigerators, water heaters) have become a major research focuses due to their quick disconnection and energy storage characteristics. The centralized control strategy of air conditioning load is put forward by establishing the linear relationship between the target temperature adjustment value and micro-grid frequency variation in [4]. The method of frequency regulation from air conditioners has little impacts on customer comforts and its feasibility is verified. In [5-7], considering customer comforts, a variable participation degree control strategy based on thermostatically controlled loads is proposed which participates in micro-grid frequency regulation through controlling thermostatically controlled loads commitment. At present, the relevant research mainly focuses on verifying whether thermostatically controlled loads coordination energy storage system can improve micro-grid frequency, which ignores the improvement of the frequency regulation capability of thermostatically controlled loads and the further optimization of the frequency modulation results.

In this paper, taking air conditioners for example, to maximize the use of cluster air conditioning and consider customer comforts, when micro-grid frequency decreases, trigger temperature of air conditioning load is increasing based on its set value. And when micro-grid frequency increases, trigger temperature of air conditioning load is decreasing based on its set value. These two kinds of processes are achieved by establishing quadratic function model between air conditioning 
compressor commitment trigger temperature and system frequency variation, which combines with energy storage system to further optimize frequency modulation results.

\section{Isolated Micro-grid System and Its Control Structure}

Isolated micro-grid system consists of photovoltaic system, wind generator, battery, uncontrollable loads and air conditioners as the representative of thermostatically controlled loads which can participate in micro-grid frequency regulation. Thermostatically controlled loads can provide limited frequency regulation capacity owing to being restricted by temperature limits and start and stop interval time. Therefor, thermostatically controlled loads and energy storage system are used to optimize the system frequency jointly based on the micro-grid hierarchical control structure in this paper. The hierarchical control configuration of micro-grid is shown in Fig.1.

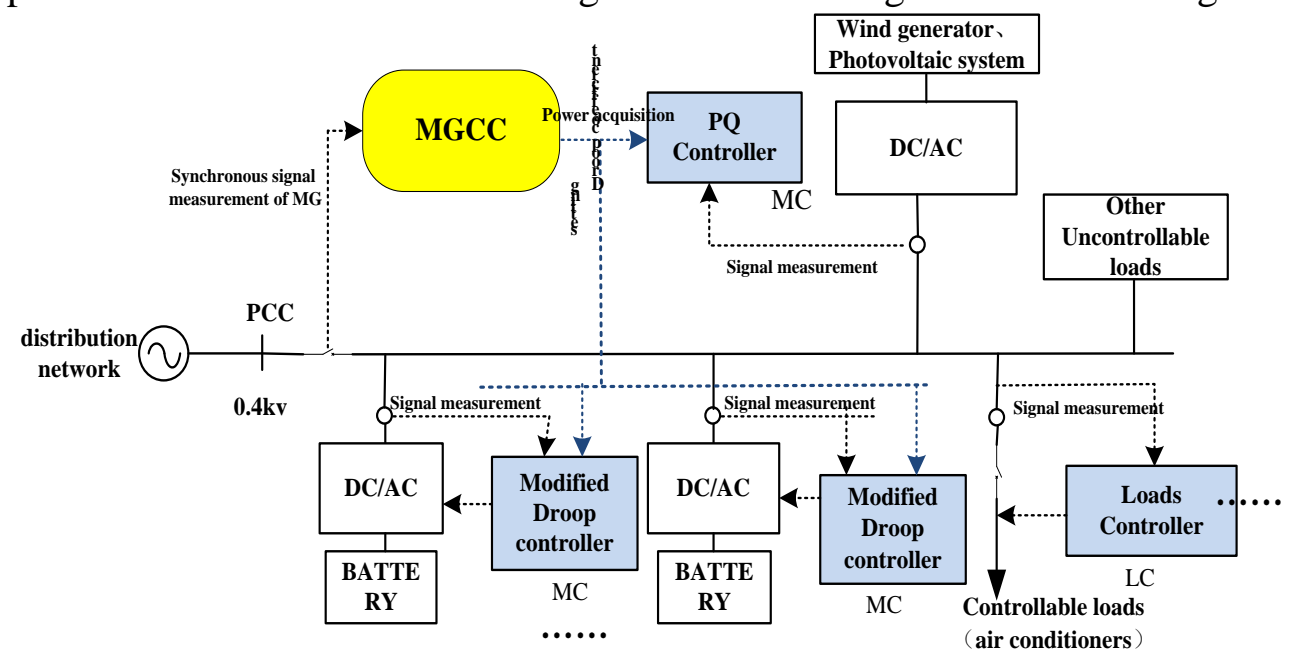

Fig. 1 The hierarchical control structure of isolated micro-grid

In Fig.1, the Distributed Generator (DG) controllers and load controllers belong to local controllers, which all have the capability of primary frequency regulation. And DG controllers and load controllers can control the response degree of the energy storage system and the switching state of the thermostatically controlled loads by the measurement signals of family intelligent measurement system obtaining control command of DG and thermostatically controlled loads. Thermostatically controlled loads take part in micro-grid operation control, which can effectively reduce the construction and use cost of the energy storage system. Micro-grid Central Controller (MGCC) has the capability of secondary frequency regulation which uses the communication system to carry out real-time scheduling on micro-grid operation and focuses on eliminating the steady state error of the system frequency and voltage. After detecting the system frequency deviation signal, MGCC utilizes secondary frequency regulation strategy of energy storage system to optimize primary frequency regulation result which is achieved by thermostatically controlled loads and energy storage system.

\section{Thermostatically Controlled Load Model and Working Principle}

Taking air conditioning as an example, the heat exchange principle is that the electric power is converted to thermal power, and the process of indoor and outdoor heat exchange follows the principle of energy balance. Assuming that the energy loss is negligible in the conversion of power and heat, and electric power is all converted into heat. Consequently, the first order dynamic mathematical model of air conditioning is shown in equation (1) (2) [4].

$$
C \dot{T}_{\text {in }}(t)=\frac{1}{R}\left(T_{\text {en }}(t)-T_{\text {in }}(t)\right)-P_{N} \cdot s(t)
$$




$$
s\left(t_{n+1}\right)= \begin{cases}0, & T<T_{-} \\ 1, & T>T_{+} \\ s\left(t_{n}\right), & T_{-}<T<T_{+}\end{cases}
$$

where $T_{\text {in }}(t)$ is the indoor temperature, ${ }^{\circ} \mathrm{C}$; $T_{e n}(t)$ is the ambient temperature, ${ }^{\circ} \mathrm{C}$; $C$ is the specific heat capacity of indoor wall; $R$ is the thermal resistance of indoor wall; $s(t)$ is the value of air conditioner working state (1 or 0 ); $P_{N}$ is the rated power of air conditioner, $k W . T_{+}$is the upper trigger temperature of air conditioner, ${ }^{\circ} \mathrm{C}$; $T_{-}$is the lower trigger temperature of air conditioner, ${ }^{\circ} \mathrm{C}$.

From equation $(1) \sim(2)$, air conditioning temperature and power demand change over time in Fig.2. The air conditioner temperature $T$ varies in a pre-set range $\left[T_{L}, T_{H}\right]$. And its working temperature is 26 degrees, and power demand is $1500 \mathrm{~W}$. When air conditioner is turned off, its temperature is 24 degrees, and power demand is $0 \mathrm{~W}$.

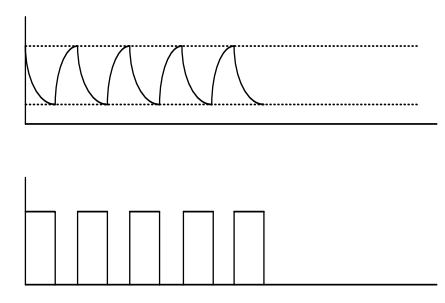

Fig. 2 Power demand and temperature changes during air-conditioning working

\section{Frequency Regulation Strategy of Thermostatically Controlled Load}

Taking air conditioning as an example, based on the energy storage characteristics of air conditioning, the short-term adjustment of the air conditioning working status will not affect the customer comforts. Thus, the cluster air conditioning can be like the generator to response frequency changes and participate in power grid frequency modulation.

According to the changes of micro-grid frequency, and considering customer comforts, short-term adjustment of the air conditioning trigger temperature setting value can make the working condition of air conditioning vary, change the power consumption of cluster air conditioning, and assist energy storage system to maintain the frequency of the micro-grid stable. Assuming that the change value of air conditioner trigger temperature is respectively $\Delta T_{\text {on }} 、 \Delta T_{\text {off }}$ when the system frequency is down and up. And the relationship between the change value of trigger temperature and the frequency of micro-grid is shown in equation (3) (4).

$$
\begin{gathered}
\Delta T_{\text {on }}=p_{\text {fon }}\left|f_{\text {meas }}-f_{N}\right| \\
\Delta T_{\text {off }}=p_{\text {foff }}\left(f_{\text {meas }}-f_{N}\right)
\end{gathered}
$$

where $f_{\text {meas }}$ is the measured frequency, $\mathrm{Hz} ; f_{N}$ is the rated frequency, $50 \mathrm{~Hz} ; p_{\text {fon }} 、 p_{\text {foff }}$ is the customer participation degree when the system frequency drops and increases, ${ }^{\circ} \mathrm{C} / \mathrm{Hz}$.

When cluster air conditioning is in stable operation state and air conditioning temperature is in the uniform distribution in the $\left[T_{l}, T_{h}\right]$, the cluster air conditioning has a relatively stable power consumption. When the frequency of the micro-grid deviates from the rated frequency, the power variation of cluster air conditioner is shown in equation (5).

$$
\Delta P_{A C}=\left\{\begin{array}{l}
\frac{\Delta T_{o n}}{T_{+}-T_{-}} \cdot P_{N} \cdot N \cdot \text { on } \%,\left(T_{-}-T_{+}\right)<\Delta T<0 \\
\frac{\Delta T_{\text {off }}}{T_{+}-T_{-}} \cdot P_{N} \cdot N \cdot \text { off } \%, 0 \leq \Delta T<\left(T_{+}-T_{-}\right)
\end{array}\right.
$$

where $\Delta P_{A C}$ is the power variation of the air conditioners; $P_{N}$ is the rated power of air conditioner; $N$ is the number of cluster air conditioner; on\%(off \%) is the percentage of air conditioners under state “on”(“off”). 
According to the primary frequency modulation characteristic of the generator, frequency modulation characteristics of cluster air conditioner with the system frequency dropping and increasing are all in accordance with the characteristics of primary frequency modulation of the generator[8]. Considering the customer comforts, when the decrement and increment of system frequency is the same, the trigger temperature variation $\Delta T_{\text {on }} 、 \Delta T_{\text {off }}$ of air conditioning load will be different, the number of air conditioning participated in system frequency regulation will be different. Therefor, power consumption of cluster air conditioning is different.

In order to avoid the impact of the number of air conditioners participated in system frequency regulation on the micro-grid stability, it is needed to make the air conditioning frequency modulation process have nothing to do with the number of air-conditioning. Air conditioner trigger temperature variation is required to reset in equation (3) (4) based on ensuring customer comforts and achieving maximum utilization of cluster air conditioning. And readjustment value of the air-conditioning trigger temperature is shown in equation (6) (7).

$$
\begin{aligned}
& \Delta T_{\text {on }}^{\prime}=\frac{p_{f}}{N}\left|f_{\text {meas }}-f_{N}\right| \\
& \Delta T_{\text {off }}^{\prime}=\frac{p_{f}}{N}\left(f_{\text {meas }}-f_{N}\right) \cdot \frac{\text { on } \%}{\text { off } \%}
\end{aligned}
$$

At this point, when the micro-grid frequency decreases and rises, the power change value of cluster air conditioning is shown in equation (8).

$$
\Delta P_{A C}=\frac{P_{N} \text { on } \%}{T_{+}-T_{-}} \cdot p_{f}\left|f_{\text {meas }}-f_{N}\right|
$$

In equation (8), $p_{f}$ is the customer participation degree after resetting the air conditioner trigger temperature. Adjusting the value of the user participation degree $p_{f}$ can give full play to frequency modulation effect of the cluster air conditioning and meet the load demand of micro-grid. Considering user comfort when the user is involved in frequency modulation, $p_{f}$ is designed as a linear function which is proportional to the frequency deviation of micro-grid in equation (9).

$$
p_{f}=k_{f}\left|f_{\text {meas }}-f_{N}\right|
$$

where $k_{f}$ is the customer participation coefficient. Adjusting the user participation coefficient $k_{f}$ can makes the cluster air conditioning give full play role in frequency regulation effect, thereby reduces frequency modulation output capacity of generating unit.

When the system frequency decreases, the trigger temperature of the air conditioning is increasing on the basis of its set value, and the frequency modulation strategy is shown in the equation (10) (11).

$$
\begin{aligned}
& T_{+}^{\prime}=T_{+}+\frac{1}{N} k_{f}\left(f_{\text {meas }}-f_{N}\right)^{2} \\
& T_{-}^{\prime}=T_{-}+\frac{1}{N} k_{f}\left(f_{\text {meas }}-f_{N}\right)^{2}
\end{aligned}
$$

When the system frequency rises, the trigger temperature of the air conditioning will reduce on the basis of its set value, and the frequency modulation strategy is shown in the equation (12) (13).

$$
\begin{aligned}
T_{+}^{\prime} & =T_{+}-\frac{1}{N} \cdot \frac{\text { on } \%}{\text { off } \%} k_{f}\left(f_{\text {meas }}-f_{N}\right)^{2} \\
T_{-}^{\prime} & =T_{-}-\frac{1}{N} \cdot \frac{\text { on } \%}{\text { off } \%} k_{f}\left(f_{\text {meas }}-f_{N}\right)^{2}
\end{aligned}
$$

From formulas $(10) \sim(13), T_{+}^{\prime} 、 T_{-}^{\prime}$ are respectively maximum trigger temperature and minimum trigger temperature of air conditioning by readjusting. Therefor, adjusting the customer participation 
coefficient $k_{f}$ can meet the load demand of micro-grid, which has nothing to do with the number of air conditioner involved and make full play to frequency modulation effect of the cluster air conditioning to response the change of system frequency.

\section{Simulation Results}

Micro-grid system consists of photovoltaic system, wind generator, battery, uncontrollable loads and air conditioners as the representative of thermostatically controlled loads. Taking the air conditioning participated in system frequency regulation as an example, a $0.4 \mathrm{kv}$ isolated micro-grid is built using DIgSILENT software. The simulation time is set to 200min, and air conditioners participated in the frequency control of micro-grid have 400 units.

The frequency control effect of the cluster air conditioning in coordination with battery under different frequency regulation methods is shown in Fig.3. From Fig.3 known, it can be known that the cluster air conditioner does not participate in the micro-grid frequency modulation, and only battery energy storage participates in frequency modulation, the frequency distribution range is $[49.90 \mathrm{~Hz}$, $50.10 \mathrm{~Hz}$ ]. When cluster air conditioning is involved in primary frequency modulation of micro-grid in coordination with battery, the frequency is mainly distributed in [49.923Hz, $50.10 \mathrm{~Hz}]$.

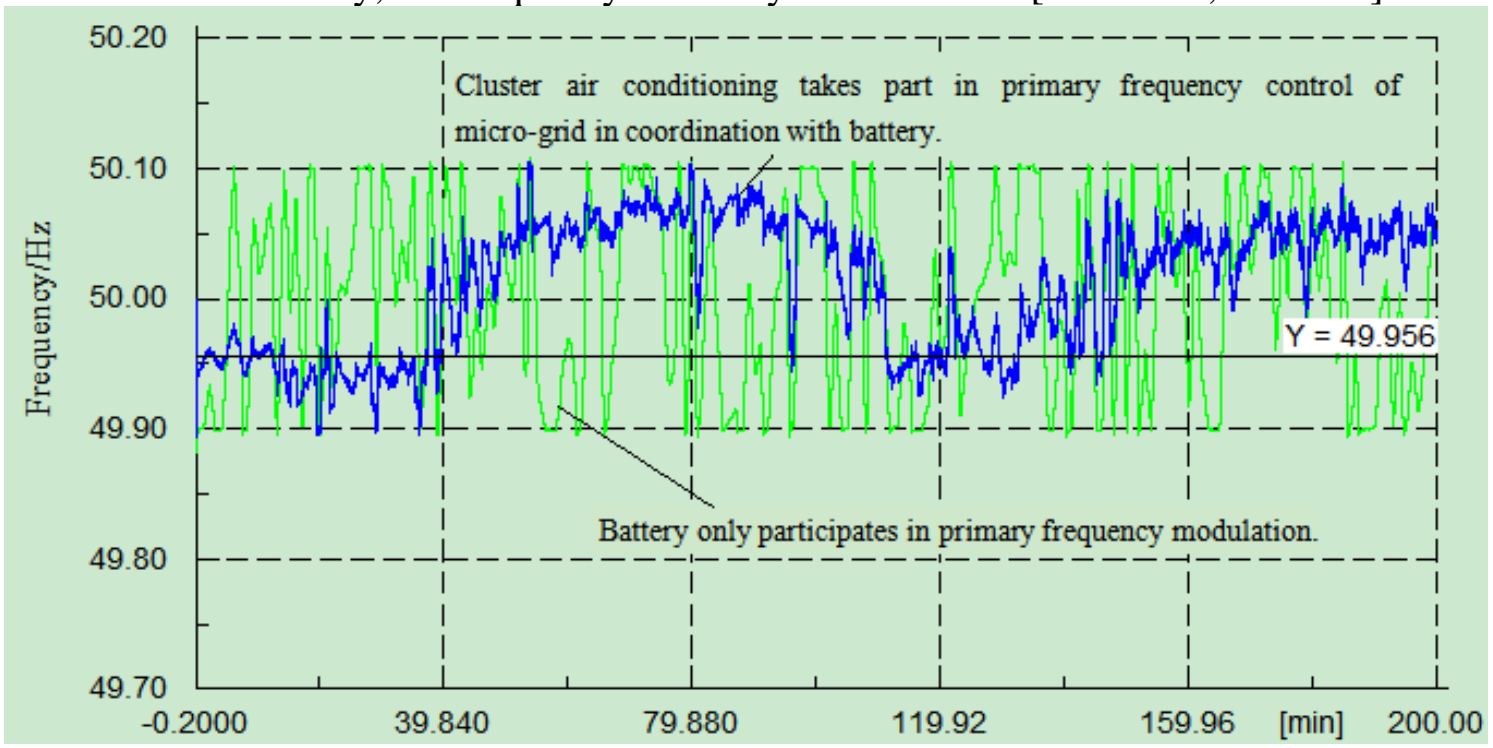

Fig.3 The frequency modulation effect of micro-grid by different frequency regulation methods

From above known, the rapid response characteristic of cluster air conditioner is reflected, and when the cluster air conditioner take part in micro-grid frequency regulation in coordination with frequency modulation strategy of battery, micro-grid frequency fluctuation decreases gradually. And the results of primary frequency modulation of micro-grid by cluster air conditioning in coordination with battery achieving can effectively improve the frequency control effect of micro-grid.

The output power curves of battery are shown in Fig.4 when the cluster air conditioning is in coordination with battery under different frequency regulation methods to adjust the system frequency. From Fig.4 known, it can be known that the cluster air conditioner is not involved in the micro-grid frequency modulation, and only battery energy storage participates in frequency modulation, the output power range of battery is [-0.10MW, $0.123 \mathrm{MW}]$. And the battery has been in a state of charge and discharge alternately. When cluster air conditioning participates in primary frequency modulation of micro-grid in coordination with battery, the output power of battery is mainly distributed in [-0.039MW, 0.105MW]. The battery has been in a state of discharge in 0 79.599min. And the battery has been in a state of discharge in 79.599 200min. Thus, when cluster air conditioner participates in frequency modulation, depth of charge and discharge on battery and the output power fluctuations of battery are reducing, which can effectively reduce the demand of capacity utilization on battery, prolong its lifetime and cut down the construction cost of micro-grid. 


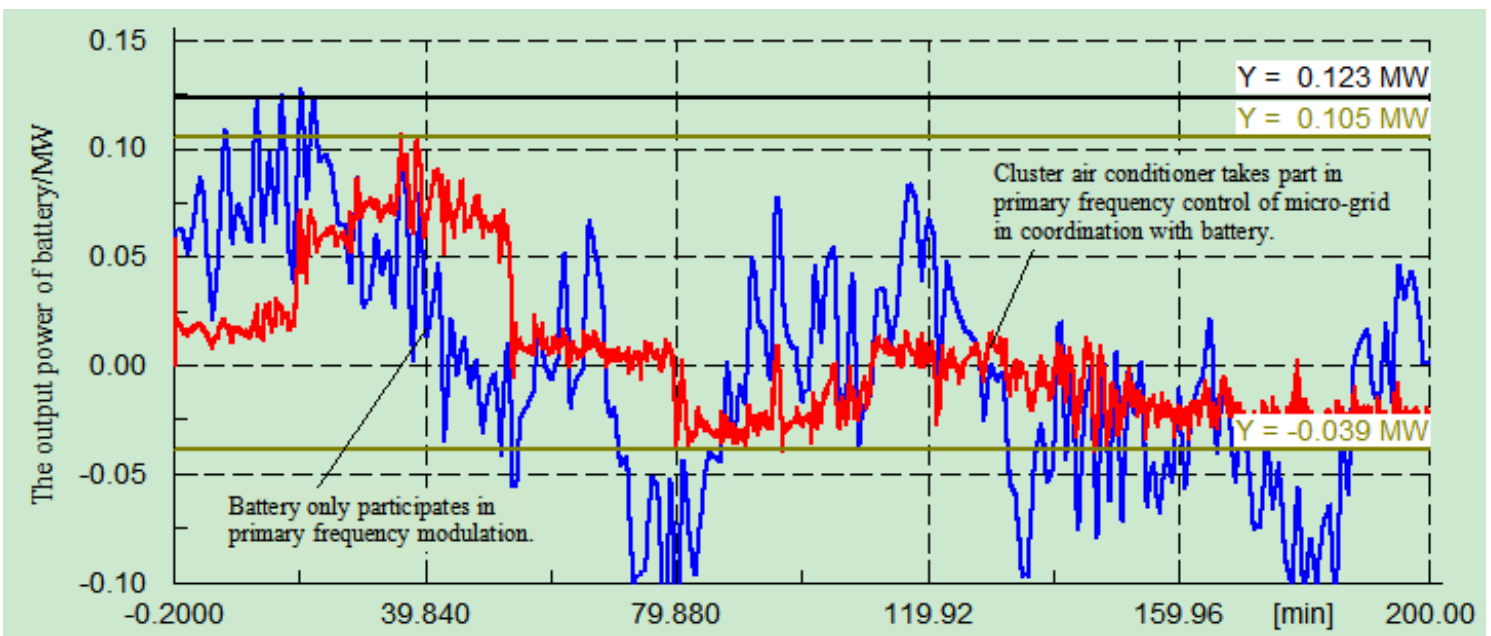

Fig. 4 The battery power curves by different frequency regulation methods

\section{Conclusions}

This paper presents a case study of air conditioning. It is proposed that the frequency modulation method of cluster air conditioner can achieve utilization of cluster air conditioning during the frequency regulation. And this method can not only effectively improve the frequency control effect for micro-grid and make the system frequency optimize but reduce capacity requirement of energy storage system by giving play to the frequency modulation effect of cluster air conditioner.

\section{Acknowledgments}

This work is supported by the Education Committee of Beijing basic research program of China(X N097) and Foundation of Collaborative Innovation Center of Key Power Energy-Saving Technolog ies in Beijing (PXM2016_014212_000016).

\section{References}

[1] Xin Jieqing, Wu Liang. Hierarchical strategies for duty cycling control of air conditioners in business buildings[J]. Automation of Electric Power Systems, 2013, 37(5): 49-54(in Chinese).

[2] Zhou Lei, Li Yang, Gao Ciwei. Improvement of Temperature Adjusting Method for Aggregated Air-conditioning Loads and Its Control Strategy[J]. Proceedings of the CSEE, 2014, 34(31): 5579-5589.

[3] Zhang Qin, Wang Xifan, Wang Jianxue, etal. Survey of demand response research in deregulated electricity markets[J]. Automation of Electric Power Systems, 2008, 32(3): 97-106(in Chinese).

[4] Li Na, Wang Xiaoliang. Research of air conditioners providing frequency controlled reserve for microgrid [J]. Power System Protection and Control. 2015, 43(19): 101-105.

[5] Jia Hongjie, Qi Yan, Mu Yunfei. Frequency control method based on household temperature control load for isolated micro grid[J]. Science in China: Science and technology, 2013, 43(3): 247-256.

[6] Khalid Elamari, Luiz A.C.Lopes. Frequency based control of electric water heaters in small PV-Diesel hybrid MINI-Grids[J]. Canadian Conference on Electrical and Computer Engineering, 2012.

[7] Z.Xu, J. Østergaard, M. Togeby. Design and modelling of thermostatically controlled loads as frequency controlled reserve[J]. 2007. 
[8] Tang Yi, Deng Keyu, Sun Huadong, Yi Jun, He Qing. Research on Coordination Scheme for Smart Household Appliances Participating Under frequency Load Shedding[J]. Power System Technology, 2013, 37(10): 2861-2867. 